\title{
Constelações: Jogo de cartas táteis para o ensino de alunos com deficiência visual
}

\author{
Constellations: Tactile card game for teaching visually impaired students \\ Constelaciones: Juego de cartas táctiles para enseñar a estudiantes con discapacidad visual
}

Recebido: 05/04/2021 | Revisado: 12/04/2021 | Aceito: 18/04/2021 | Publicado: 03/05/2021

\author{
Rose Cristina Alves Nunes \\ ORCID: https://orcid.org/0000-0002-2674-2948 \\ Universidade Federal do Pampa, Brasil \\ E-mail: rosecristinaanunes@gmail.com \\ Carlos Maximiliano Dutra \\ ORCID: https://orcid.org/0000-0003-4743-874X \\ Universidade Federal do Pampa, Brasil \\ E-mail: profcarlosmaxdutra@gmail.com
}

\begin{abstract}
Resumo
O presente trabalho visa demonstrar o passo a passo da construção de um jogo didático tátil para alunos com deficiência visual (DV) que estejam incluídos em salas regulares de quinto ano do Ensino Fundamental. As cartas táteis foram produzidas para colaborar com a aprendizagem e possibilidade de abstração do conteúdo das "Constelações do Zodíaco" de Astronomia. Para a confecção do jogo adaptado, foram utilizadas imagens como referências visuais e recursos de baixo custo. Para a otimização do processo, contamos com o auxílio de um acadêmico com DV, com prévio manuseio de diferentes materiais sugeridos para a produção do jogo didático, indicando assim, as melhores percepções quanto às dimensões e sensações táteis a serem utilizados para a identificação das constelações e posição das transcrições em Braille. A partir do processo descrito de construção deste recurso, afirmamos que os materiais táteis elaborados, atingiram os propósitos ao serem aplicados ao aluno com DV participante, estimulando o seu processo de aprendizagem da temática voltada ao ensino de Astronomia, pois definições sobre as constelações podem ser consideradas complexas para alunos com DV, sendo praticamente impossível desenvolver a noção dessas características sem o auxílio de diferentes ferramentas. Esta pesquisa aplicada constata que na área do ensino em Ciências ainda há necessidade de produção de jogos táteis adaptados e recursos didáticos aos alunos com DV para melhor consciência dos fenômenos que nos cercam.
\end{abstract}

Palavras-chave: Astronomia; Carta tátil; Deficiência Visual; Material adaptado tátil.

\begin{abstract}
The present work aims to demonstrate the step by step of the construction of a tactile educational game for students with visual impairment (DV) who are included in regular classrooms of the fifth year of Elementary School. The tactile charts were produced to collaborate with the learning and possibility of abstraction of the content of the "Constellations of the Zodiac" of Astronomy. For the creation of the adapted game, images were used as visual references and low-cost resources. For the optimization of the process, we count on the help of an academic with DV, with previous handling of different materials suggested for the production of the didactic game, indicating, thus, the best perceptions regarding the dimensions and tactile sensations to be used for the identification of the constellations and position of transcripts in Braille. From the described process of construction of this resource, we affirm that the tactile materials elaborated, reached the purposes when applied to the student with participating DV, stimulating their learning process of the theme focused on the teaching of Astronomy, because definitions about the constellations can be considered complex for students with DV, being practically impossible to develop the notion of these characteristics without the aid of different tools. This applied research finds that in the area of science education there is still a need for the production of adapted tactile games and teaching resources for students with DV for better awareness of the phenomena that surround us.
\end{abstract}

Keywords: Astronomy; Tactile chart; Visual impairment; Adapted tactile material.

\section{Resumen}

El presente trabajo tiene como objetivo demostrar el paso a paso de la construcción de un juego educativo táctil para estudiantes con discapacidad visual (DV) que se encuentran incluidos en las aulas regulares de quinto año de Educación Primaria. Las cartas táctiles fueron producidas para colaborar con el aprendizaje y la posibilidad de abstracción del contenido de las "Constelaciones del Zodíaco" de Astronomía. Para la creación del juego adaptado se utilizaron imágenes como referencias visuales y recursos de bajo costo. Para la optimización del proceso, contamos con la ayuda de un académico con DV, con el manejo previo de los diferentes materiales sugeridos para la producción del juego didáctico, indicando, así, las mejores percepciones en cuanto a las dimensiones y sensaciones táctiles a utilizar para la identificación de las constelaciones y la posición de las transcripciones en Braille. A partir del proceso 
de construcción descrito de este recurso, afirmamos que los materiales táctiles elaborados, alcanzaron los propósitos al ser aplicados al alumno con DV participante, estimulando su proceso de aprendizaje de la temática enfocada a la enseñanza de la Astronomía, pues las definiciones sobre las constelaciones pueden Ser considerado complejo para los estudiantes con VD, siendo prácticamente imposible desarrollar la noción de estas características sin la ayuda de diferentes herramientas. Esta investigación aplicada encuentra que en el área de la educación científica aún existe la necesidad de la producción de juegos táctiles adaptados y recursos didácticos para estudiantes con VD para una mejor conciencia de los fenómenos que nos rodean.

Palabras clave: Astronomía; Gráfico táctil; Discapacidad visual; Material táctil adaptado.

\section{Introdução}

Nas últimas décadas, o Brasil legitimou mudanças conceituais e estruturais voltadas à perspectiva educacional inclusiva. Podemos afirmar que este processo de iniciativas permitiu avanços no ingresso de pessoas com deficiência visual (DV) em escolas de ensino regular, através da Portaria nº 2.678 (Brasil, 2002) com a regulamentação do uso, ensino, produção e difusão do sistema Braille em todas as modalidades de ensino. E subsequentemente através da "Política Nacional de Educação Especial na Perspectiva da Educação Inclusiva” (Brasil, 2008), que passou a orientar os sistemas educacionais no que se refere à organização dos serviços e recursos da Educação Especial, estabelecendo com clareza o Atendimento Educacional Especializado (AEE) em Salas de Recursos Multifuncionais (SRM), detalhando os conhecimentos específicos que os profissionais do AEE necessitam para atuar com estudantes com Deficiência Visual (DV) em turno inverso as aulas regulares recebidas e também desenvolvendo juntamente com os demais professores estratégias e adaptações necessárias ao desenvolvimento de suas aprendizagens.

Temos ainda, a Lei Brasileira de Inclusão da Pessoa com Deficiência (Brasil, 2015), que visa assegurar o sistema educacional inclusivo para a pessoa com deficiência em todos os níveis de ensino e instituições privadas, oportunizando condições de acesso, permanência, participação e aprendizagem.

O desenvolvimento da pessoa com DV tem particularidades que precisam ser conhecidas e consideradas, pesquisas sugerem que a criança com DV poderá apresentar desenvolvimento normal, desde que não seja privada de experiências sensoriais, motoras, cognitivas e sociais significativas. Sendo assim, necessário contar com serviços de detecção e intervenção precoce, assistência à criança e família e instrumentalização dos professores para utilizar recursos que promovam a participação plena nas atividades da escola (Laplane; \& Batista, 2008).

Conforme o Decreto de Lei $\mathrm{n}^{\circ}$ 5.296, de 2004, é considerado cego, quem apresentar acuidade visual igual ou inferior a 0,05 no melhor olho, com a melhor correção óptica, com alguma consequência irremediável: na percepção de cor, tamanho, distância, forma, posição ou movimento. Com baixa visão, quem possuir acuidade visual entre 0,3 e 0,05 no melhor olho, com a melhor correção óptica ou quando a somatória da medida do campo visual de ambos os olhos for igual ou inferior a $60^{\circ}$ ou que acumule a ocorrência de quaisquer das condições mencionadas. Dessa maneira, a baixa vi são, deve ser considerada caso a caso em função da variedade e intensidade dos comprometimentos relacionados às funções visuais. Nessas situações, a execução de tarefas e o desempenho geral do indivíduo se vê afetado devido a dificuldades de percepção de luz, redução da acuidade e do campo visual (Brasil, 2007).

Porém, ainda é possível constatar, que muitas vezes há um distanciamento entre o prescrito nas leis e documentos e o que de fato é efetivado no cotidiano dos estabelecimentos de ensino (Mazzotta, 2011), pois quando há a falta de material adaptado, existe apenas a fala do professor como único meio de aprendizagem (Nunes, 2004). Tal afirmação se confirma, através da análise de pesquisas que investigam esse fenômeno como a de Costa (2012), Pansini \& Matos (2014), Menezes (2008), Duek (2011), Camargo (2008) e Urzêda (2012) as quais denunciam que muitos estudantes com deficiência não estão inclusos por falta de condições adequadas para a efetivação do processo educacional (Uliana; \& Mól, 2017).

Crianças cegas congênitas têm domínio do tato para "ler" imagens, as mãos são suas maiores ferramentas para 
exploração, percepção e reconhecimento do mundo à sua volta. Para Ruiz e Batista (2014), durante a leitura de imagens táteis (desenvolvidas para serem lidas com as mãos), as crianças demonstram a capacidade de decodificar elementos em relevo, mostrando que o grande problema não está nelas, mas na falta de compreensão sobre as peculiaridades cognitivas da cegueira.

Conforme os autores Uliana e Mól (2017), as pesquisas diagnósticas de Baumel (1990), Gasparetto (2001), Gorgetti (2005), Mazzaro (2007) e Dorneles (2014), em que ouviram professores e profissionais de escolas que apresentarem suas percepções sobre o processo de inclusão de estudantes com DV. Apesar das pesquisas terem sido desenvolvidas em localidades e anos diferentes, as conclusões dos autores se convergiram à falta de preparação docente para a prática pedagógica com estudantes com DV e a escassez de material didático nas escolas para o ensino das diferentes disciplinas do currículo escolar.

Há pouquíssimos materiais ilustrativos funcionais e inclusivos para alunos com DV, já que algumas disciplinas têm conteúdo muito abstrato para a compreensão sem material de apoio adequado (Pagano; \& Martins, 2014). O professor da sala regular deve considerar que o aluno com DV, necessita de recursos didáticos concretos, atrativos e construídos a partir da demanda dos conteúdos e contexto ao qual estão inseridos (Dallabona, 2011). Podendo ser definido como recurso didático todo e qualquer material empregado para auxiliar no processo de ensino aprendizagem com embasamento teórico, aliado ao planejamento do professor para que os objetivos sejam alcançados (Piletti, 2004; Souza \& Dalcolle, 2007).

Considerando a importância da aprendizagem de conteúdos de Ciências para a formação de sujeitos críticos e atuantes na sociedade, é necessário motivar o estudante, seja ele vidente ou com DV através de atividades estimulantes (Pimentel; \& Aragon, 2018). O que requer do professor outras maneiras de proporcionar aprendizagens aos seus alunos, principalmente ao aluno com DV. Pois, ensinar Astronomia requer algumas particularidades, a mesma se distingue de outras ciências, por ser basicamente visual, se encontrando além dos olhos e quase sempre, de uma maneira que dificulta a elaboração de esquemas mentais, levando muitas vezes à idealização de fenômenos ou corpos celestes (Langhi \& Nardi, 2012).

Em pesquisa no Periódicos da CAPES, levando em consideração o período de 2012 a 2016, os autores Pimentel e Aragon (2018) encontraram cento e um (101) artigos para jogos pedagógicos, dois mil, setecentos e oitenta e oito (2.788) para ensino de ciências, trezentos e quatorze (314) para deficiente visual. Dois (2) entre os artigos encontrados se relacionavam a jogos pedagógicos e deficiente visual. Vinte e três (23) eram sobre ensino de ciências para deficiente visual. No entanto, não foram encontrados artigos para os três descritores juntos.

Os autores relatam que:

Diante da escassez de trabalhos publicados no Brasil nas fontes pesquisadas, concluímos ser necessário estimular a produção acadêmica sobre o desenvolvimento e a utilização de jogos pedagógicos na área de Ciências, pois acreditamos que estes podem contribuir para a educação e socialização de alunos com deficiência visual incluídos nas escolas regulares. É importante ressaltar que tal material deve ser devidamente adaptado afim de favorecer a interação entre pessoas com e sem deficiência visual no processo de ensino e aprendizagem (Pimentel \& Aragon, 2018).

Os resultados da pesquisa de Pimentel e Aragon, servem como motivadores para que haja mais trabalhos de confecção de jogos didáticos na área de Ciências e mais especificamente Astronomia, para atingir os alunos com DV incluídos nas escolas regulares. Sendo necessário ressaltar a importância da publicação destes estudos, para estimular a construção destes recursos por professores que venham a ministrar estes conteúdos em suas aulas, ou mesmo, o surgimento de novos modelos que facilitem o acesso lúdico e tátil, pois são muitos as temáticas do ensino em Ciências que precisam e podem serem abrangidos.

Podemos dizer que os recursos didáticos são utilizados como um apoio para que o professor consiga contextuar os conceitos trabalhados e despertar no aluno a motivação em não só aprender o conteúdo, como também ser capaz de compreender sua colocação nas esferas da sociedade e ser capaz de aplicá-lo em resoluções de problemas (Costa; Silva; \& Silva, 2021), já que, "o aluno motivado busca novos conhecimentos e oportunidades, mostrando-se envolvido com o processo 
de aprendizagem, envolve-se nas tarefas com entusiasmo e demonstra disposição para novos desafios" (Alcará \& Guimarães, 2007, p. 177).

Os materiais adaptados e estratégias que incentivem o diálogo e permitam a autonomia dos alunos seriam os mais indicados para o sucesso da inclusão educacional. Conforme Moran (2018), os jogos podem ser aplicados de forma individual ou coletiva e despertam o interesse do aluno através da ludicidade que envolve o conteúdo trabalhado a uma temática que motiva os estudantes. Atualmente, a utilização de jogos por crianças e adolescentes é extremamente comum, o que torna esta atividade mais prazerosa para eles e de fácil utilização pelo professor.

Os jogos didáticos consistem em ótimas ferramentas, que possibilitam aos alunos estabelecerem relações entre os conteúdos estudados e as práticas do dia a dia, de forma lúdica e divertida (Campos et al., 2003). No caso dos alunos com DV, a elaboração e utilização de jogos em que prevaleça a discriminação tátil, informações auditivas e que contenham legendas em Braille, aproximam e facilitam o relacionamento destes com outros alunos e promovem a aproximação dos alunos ao conhecimento científico (Soares; Castro; \& Delou, 2015).

Considerando os pontos anteriormente apresentados, o presente trabalho tem por objetivo o desenvolvimento de um jogo didático tátil sobre o conteúdo de Astronomia "Constelações do Zodíaco", para ser utilizado como recurso didático por professores em aulas do quinto ano do Ensino Fundamental, o jogo produzido foi aplicado previamente e posteriormente a sua construção em um aluno com DV. Devido a pandemia, foi adiada a proposição de aplicar este jogo didático em uma sala de aula com alunos videntes tendo incluído um aluno com DV.

\section{Metodologia}

Esta é uma pesquisa aplicada, realizada a partir de objetivos que visem sua utilização prática utilizando-se da contribuição de estudos já existentes (Santos \& Filho, 2017), contribui para fins práticos, visando a solução mais ou menos imediata do problema encontrado na realidade (Barros \& Lehfeld, 2014).

A proposta do presente trabalho, teve início após fundamentação teórica de que o número de estudos voltados para a confecção de jogos táteis para alunos com DV, ainda é baixo, se comparado com materiais e jogos didáticos que envolvam outras temáticas.

Desta forma, será demonstrada a construção do jogo de Cartas táteis, trazendo o passo a passo para que os professores do ensino de Ciências que ministram conteúdos de Astronomia ou professores de AEE das SRM, que tiverem alunos com DV em suas escolas, mais especificamente em turmas de quinto ano, possam reproduzi-los, garantindo uma inclusão com possibilidade de que o aluno com DV acompanhe as aulas de Ciências e construa suas aprendizagens com qualidade.

Para a confecção das Cartas táteis, foi produzido um modelo contendo as 13 Constelações do Zodíaco para serem percebidas em relevo e 13 cartas com os nomes das Constelações, todas com a transcrição em Braille. Conforme a Base Nacional Comum Curricular (BNCC) é na área de Ciências da Natureza, unidade temática Terra e Universo, que o ensino da Astronomia deve ser contemplado, sendo também desenvolvido gradualmente em todos os anos do Ensino Fundamental (Brasil, 2017). O objeto do conhecimento "Constelações do Zodíaco", deve desenvolver mais especificamente a habilidade de identificar algumas constelações no céu, com o apoio de recursos (como mapas celestes e aplicativos digitais, entre outros) e os períodos do ano em que elas são visíveis no início da noite.

No transcorrer da pesquisa, contou-se com a participação de um acadêmico com DV, objetivando potencializar o desenvolvimento quanto às dimensões e percepções táteis das Cartas. Os materiais didáticos táteis foram construídos visando permitir que os alunos com DV, identifiquem os fenômenos astronômicos do céu, mais especificamente das constelações, de uma forma tangível, clara e dinâmica. 


\section{Resultados e Discussão}

\section{- Carta tátil como instrumento de aprendizagem}

Uma carta celeste ou mapa celeste é um mapa do céu, que pode retratar toda a extensão das 88 constelações existentes ou uma parte do céu, mostrando como ele é visto de um determinado lugar. A quantidade de estrelas observadas da Terra é tão grande que astrônomos, desde a antiguidade, dividem as estrelas em grupos para facilitar a observação. Esses grupos são chamados de constelações. Algumas constelações são mais fáceis de identificar no céu noturno por causa de suas estrelas de maior magnitude. Podendo-se afirmar, que as constelações são de grande importância para a localização de estrelas para estudos astronômicos, e a possível localização de sistemas planetários como o nosso.

O material adaptado tátil, objetiva o melhor entendimento do conteúdo de "Constelações Zodiacais", trazendo o conhecimento de que o Sol se desloca pela Eclíptica e atravessa as 13 constelações, conforme a Figura 1, onde constam os períodos do ano. Chamamos de constelações zodiacais aquelas por onde o Sol transita atualmente, de acordo com a União Astronômica Internacional (UAI em português e IAU em inglês). São denominadas constelações zodiacais: Peixes, Áries, Touro, Gêmeos, Câncer, Leão, Virgem, Libra, Escorpião, Ofiúco, Sagitário, Capricórnio e Aquário. Para o observador terrestre, a Terra parece fixa e tem-se a impressão que é o Sol que, em um ano, faz uma volta pela Esfera Celeste, percorrendo a Eclíptica que é a linha central do zodíaco (Nova Escola).

Figura 1 - Constelações do Zodíaco.

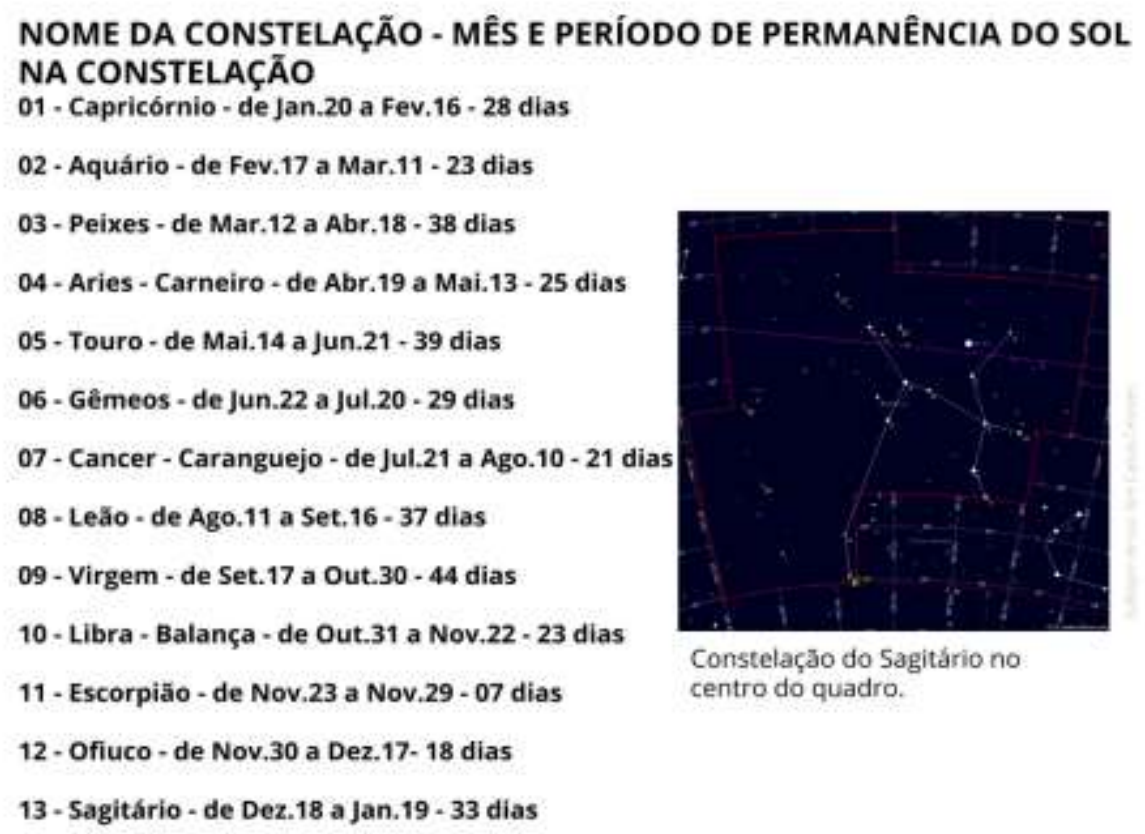

Fonte: Revista Nova Escola. https://novaescola.org.br/plano-de-aula/2773/constelacoes-do-zodiaco.

\section{- Aplicação prévia dos materiais táteis}

Para que as Cartas táteis fossem confeccionadas com boa dimensão e percepção das constelações e transcrições em Braille, foi realizada uma aplicação prévia de diferentes materiais a um aluno com DV, que frequenta o curso de Ciências da Natureza na Universidade Federal do Pampa (UNIPAMPA) de Uruguaiana.

Desta forma, foram disponibilizadas várias opções dos materiais que representam as constelações: linha comum de costura em constelação com tamanho pequeno (Figura 2A), linha 1,25mm em constelação de tamanho grande (Figura 2B), linha 1,25 mm em constelação tamanho pequeno (Figura 2C) e constelação contornada com cola colorida (Figura 2D). Sendo 
que o aluno optou pela linha de 1,25mm da Figura 2B, relatando que assim, melhoraria o estabelecimento de relações e a identificação de cada constelação. Após este momento de trocas em que se buscou compreender para atender as solicitações do aluno com DV, concluiu-se que as cartas celestes deveriam ter o tamanho de $12 \mathrm{~cm} \mathrm{X} 18 \mathrm{~cm}$, descartando-se assim as outras opções.

Figura 2 - Diferentes materiais táteis sugeridos para o aluno com Deficiência Visual realizar manuseio prévio.

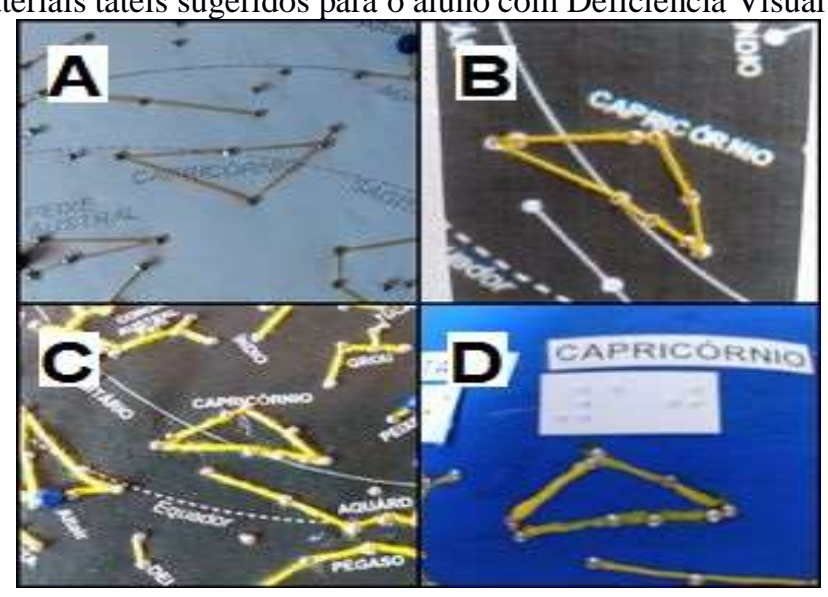

Fonte: Os autores (2019).

\section{- Confecção das Cartas táteis}

Para a confecção deste jogo didático tátil das Cartas táteis, conforme Tabela 1, utilizamos matérias de baixo custo e fáceis de serem encontrados no comércio, visando facilitar a aquisição por escolas e professores que estejam desenvolvendo este conteúdo de Astronomia.

Tabela 1 - Materiais utilizados para a confecção das Cartas táteis

\begin{tabular}{|c|c|c|}
\hline Material & Quantidade & Onde procurar? \\
\hline Figuras ampliadas das Constelações Zodiacais & 13 un. & Site: www.oba.org.br \\
\hline Placa isopor $12 \mathrm{~cm} \mathrm{X} 18 \mathrm{~cm} \mathrm{c/} 2 \mathrm{~cm}$ espessura & 26 un. & Papelaria \\
\hline EVA azul & 01 un. & Papelaria \\
\hline Cartolina japonesa azul (13 cartas $10 \mathrm{cmX} 10 \mathrm{~cm})$ & 01 un. & Papelaria \\
\hline Linha amarela $1,25 \mathrm{~mm}$ & 01 un. & Armarinho \\
\hline Agulha & 01 un. & Armarinho \\
\hline Alfinete $\mathrm{n}^{\circ} 24$ & $01 \mathrm{cx}$. & Papelaria \\
\hline Alfinete com cabeça & $01 \mathrm{cx}$. & Papelaria \\
\hline Tesoura & 01 un. & Papelaria \\
\hline Cola branca & 01 un. & Papelaria \\
\hline Cola silicone & 01 un. & Papelaria \\
\hline Folha $180 \mathrm{~g}$ & 01 un. & Papelaria \\
\hline Folha sulfite & 07 un. & Papelaria \\
\hline Reglete e punção & 01 un. & Papelaria \\
\hline
\end{tabular}

Fonte: Os autores (2019). 
Research, Society and Development, v. 10, n. 5, e18110514691, 2021

(CC BY 4.0) | ISSN 2525-3409 | DOI: https://doi.org/10.33448/rsd-v10i5.14691

\section{- Passo a passo da confecção do material tátil:}

Passo 1: Cortar o isopor em 26 unidades de placas com $12 \mathrm{~cm} \mathrm{X} \mathrm{18cm,} \mathrm{colando} \mathrm{de} \mathrm{duas} \mathrm{em} \mathrm{duas} \mathrm{para} \mathrm{que} \mathrm{fiquem} 13$ unidades com $4 \mathrm{~cm}$ de espessura cada (Figura 3).

Figura 3 - Placas de isopor cortadas.

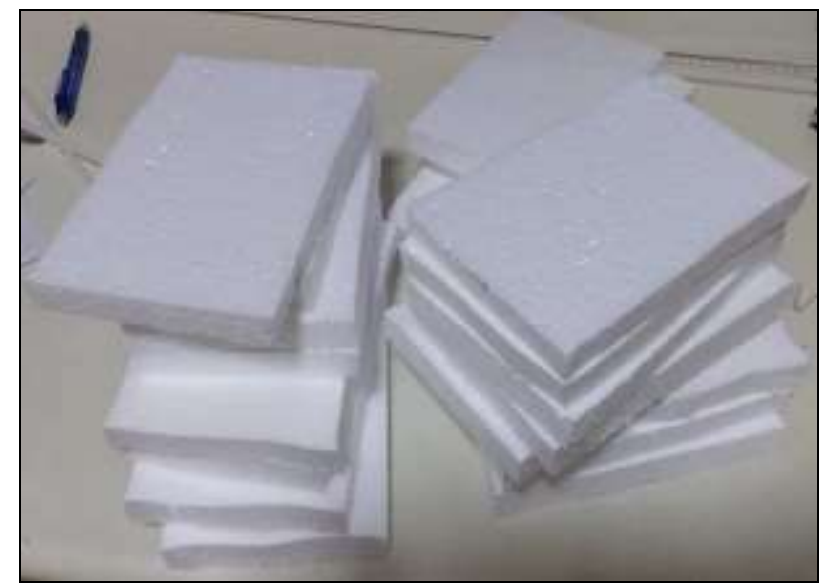

Fonte: Os autores (2019).

Passo 2: Imprimir e recortar as 13 Cartas celestes (Figura 4).

Figura 4 - Cartas celestes impressas.

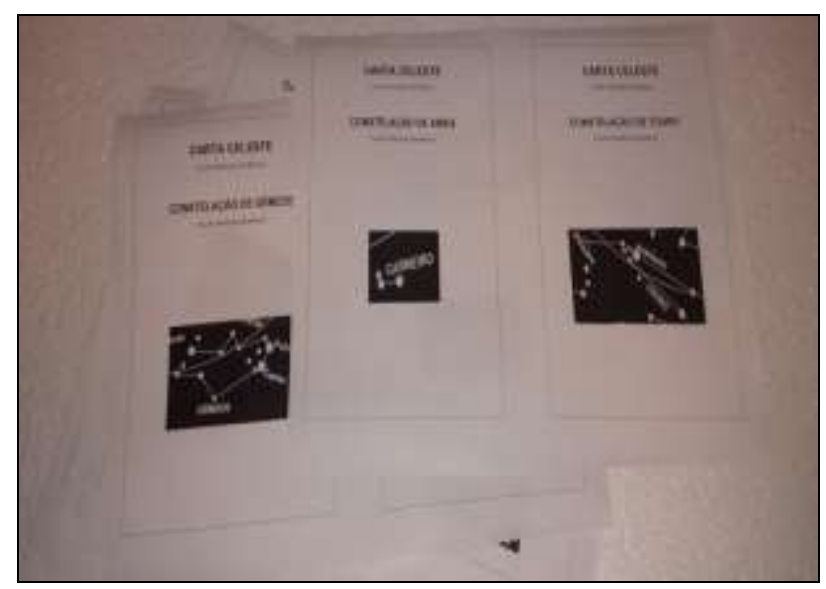

Fonte: Os autores (2019).

Passo 3: Utilizando agulha e linha 1,25mm, contornar as constelações como se estivesse fazendo uma costura (Figura $5)$. 
Research, Society and Development, v. 10, n. 5, e18110514691, 2021

(CC BY 4.0) | ISSN 2525-3409 | DOI: https://doi.org/10.33448/rsd-v10i5.14691

Figura 5 - Cartas celestes sendo contornadas com agulha e linha 1,25mm.

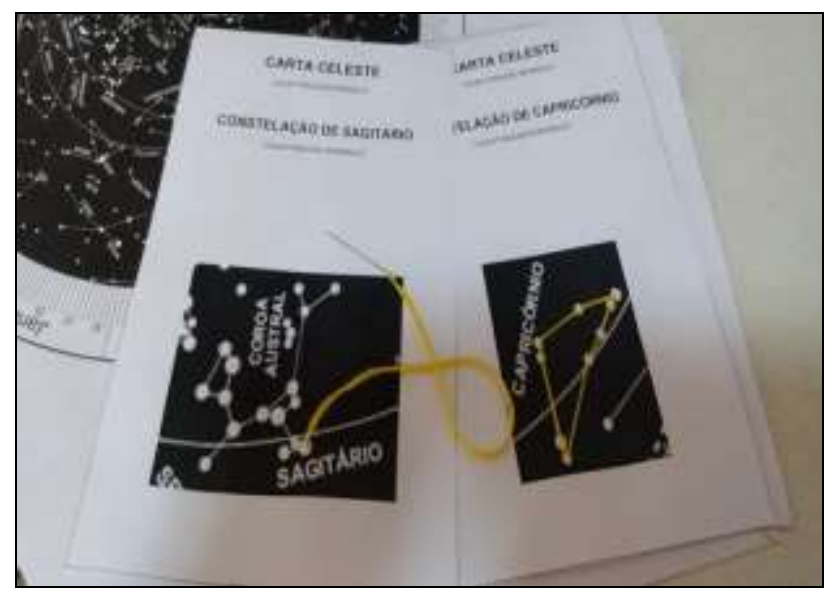

Fonte: Os autores (2019).

Passo 4: Colar com cola de silicone as tiras de EVA com $4 \mathrm{~cm}$ de largura nas laterais das placas de $12 \mathrm{~cm} \mathrm{X} 18 \mathrm{~cm}$ e com cola branca as Cartas celestes (Figura 6).

Figura 6 - Momento de colar o EVA e as Cartas celestes no isopor

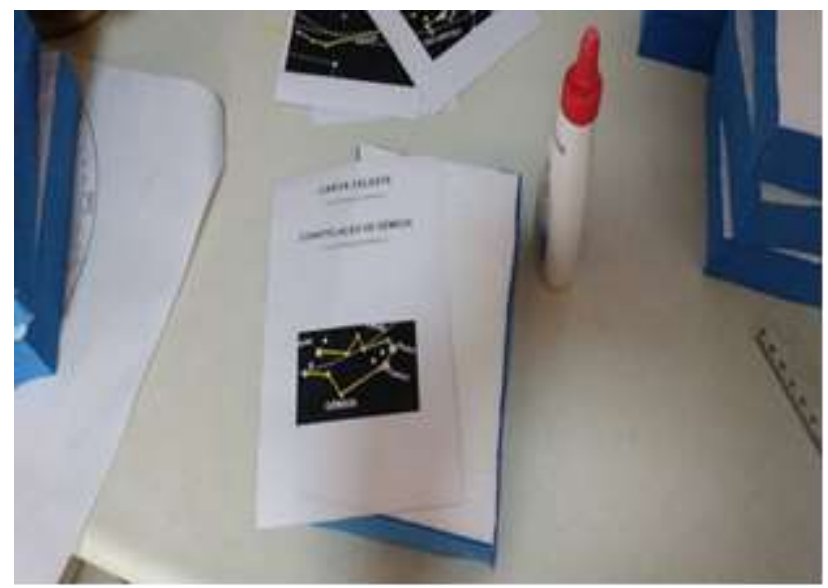

Fonte: Os autores (2019).

Passo 5: Após a cola branca secar, colocar os alfinetes nos locais que representam as estrelas, sendo que os alfinetes com cabeça representam as estrelas com maior magnitude (Figura 7).

Figura 7 - Os alfinetes representam as estrelas da constelação.

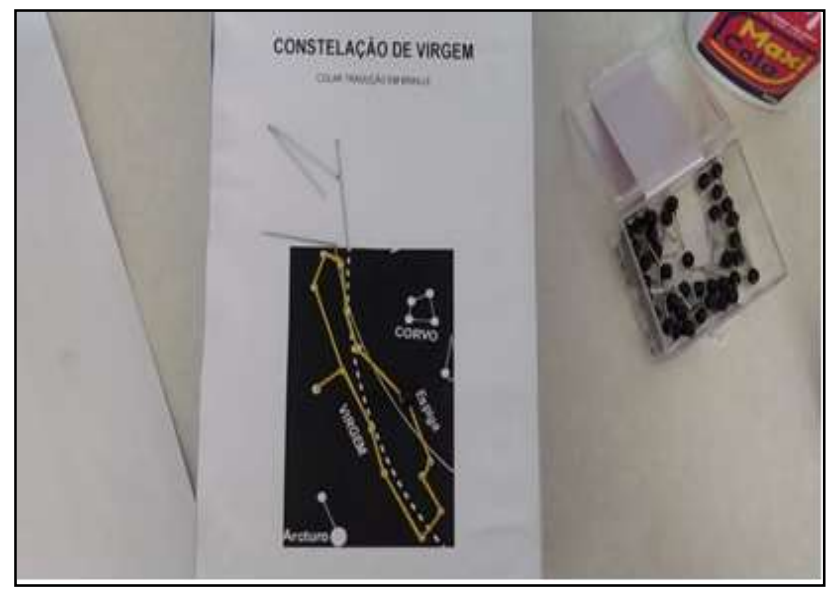

Fonte: Os autores (2019). 
Passo 6: Recortar na cartolina japonesa azul 13 cartas medindo $10 \mathrm{~cm}$ X $10 \mathrm{~cm}$, e colar os nomes das constelações.

Passo 7: Fazer a transcrição em Braille com uso da reglete e punção (Figura 8) das palavras das 26 Cartas táteis, que estão em caixa alta (Arial, 18 e 16), para também facilitarem a leitura por alunos com baixa visão. Para escrever em Braille, prende-se o papel na reglete e se escreve, pressionando com punção da direita para esquerda. Desta forma, formam os pontos em relevo do lado avesso da folha, com isso, a leitura acontece da esquerda para direita. Logo, as letras da leitura são escritas com pontos inversos, como a imagem no espelho.

Figura 8 - Reglete e punção para escrita em Braille.

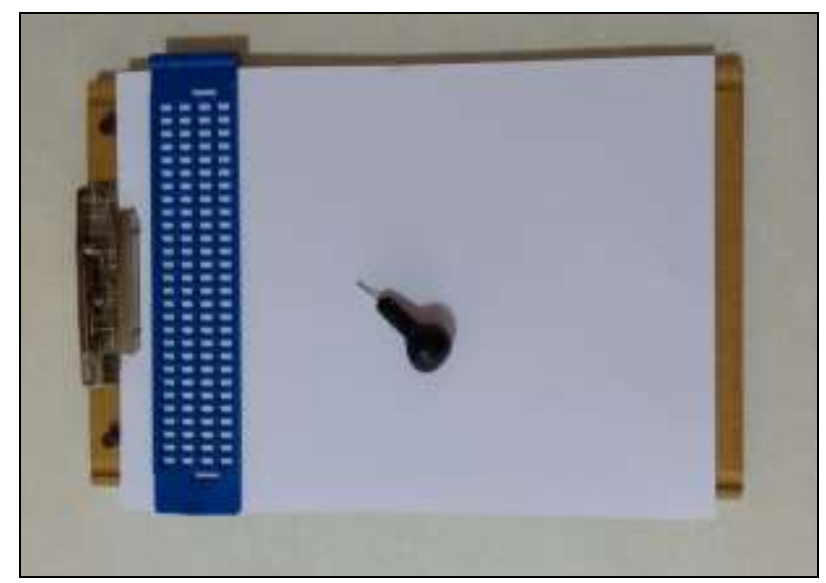

Fonte: Os autores (2019).

Passo 8: As 26 Cartas táteis finalizadas e prontas para serem utilizadas pelos alunos com DV nas aulas de Ciências com o conteúdo de Astronomia "Constelações do Zodíaco" (Figuras 9 e 10).

Figura 9 - Cartas táteis “Constelações do Zodíaco” prontas.

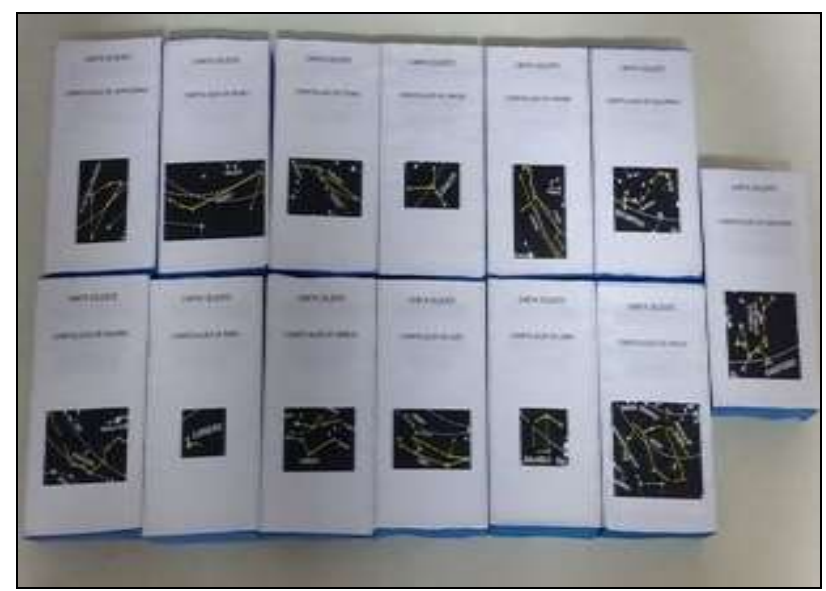

Fonte: Os autores (2019). 
Figura 10 - Cartas táteis nomes das constelações em fonte Arial 18 e Braille prontas.

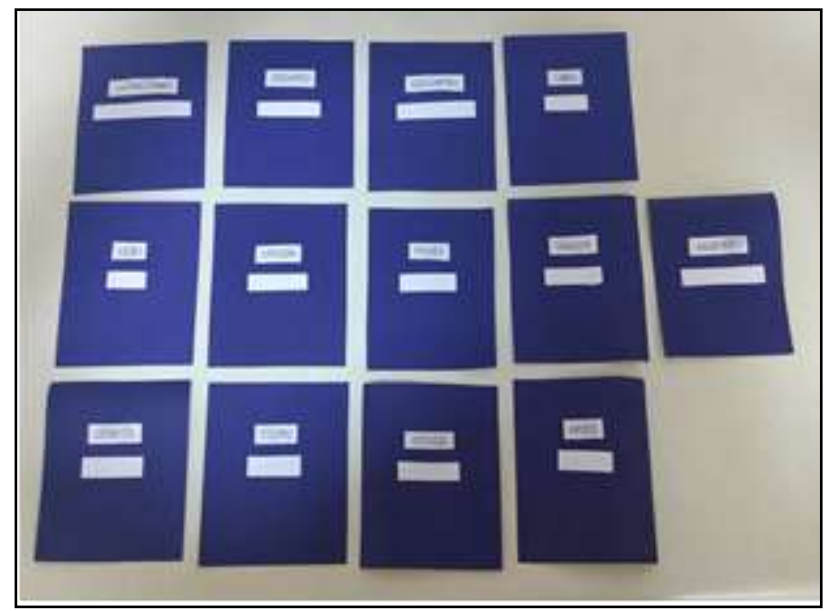

Fonte: Os autores (2019).

\section{- Resultado final}

O jogo didático das Cartas táteis finalizado conforme as solicitações prévias com diferentes materiais, tamanhos e texturas foi manuseado pelo acadêmico com DV conforme a Figura 11. A atividade teve início com a explicação oral do conteúdo feita pelo professor, porém o aluno com DV também pode ser estimulado a realizar pesquisa prévia sobre o conteúdo com uso do Dosvox (sistema destinado a auxiliar a pessoa com DV a fazer uso do computador por meio de um sintetizador de voz), ou através de conteúdo previamente transcrito em Braille. Tendo como proposição que também seja aplicado em dinâmica feita com os demais colegas da turma.

Figura 11 - Aluno deficiente visual realizando experimentação do material tátil pronto.

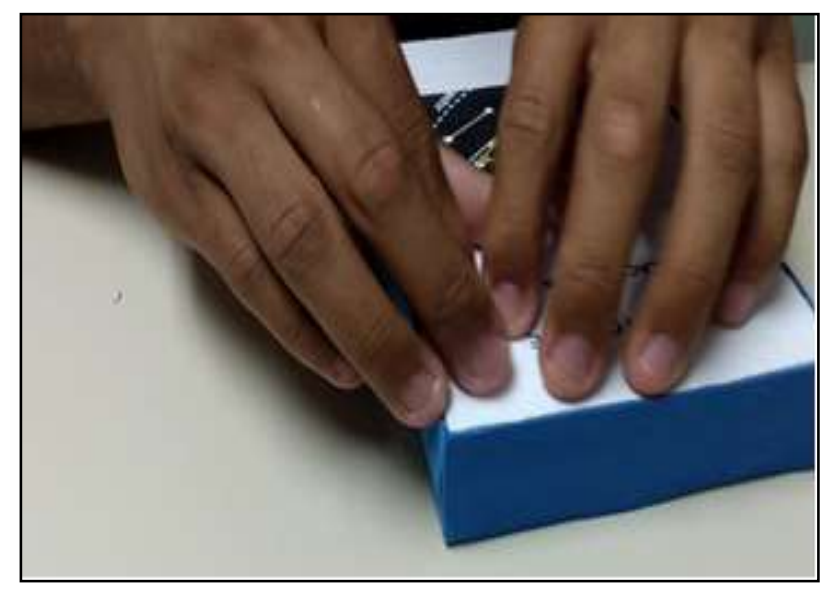

Fonte: Os autores (2019).

O aluno com DV demonstrou interesse pela atividade, como acadêmico utilizou seus conhecimentos prévios sobre a temática, também estabeleceu relação dos formatos das constelações com formas geométricas. Durante este momento de manuseio, concordou com os materiais utilizados e dimensões do jogo.

O objetivo do jogo das Cartas táteis é de que através da memória os alunos relacionem os nomes das constelações ao seu formato de conjunto de estrelas, estimulando a visualização do formato pelos alunos videntes e a identificação tátil do aluno com DV. O jogo, além de ter um formato lúdico, tem como possibilidade poder contar com a participação de todos os alunos da turma. 
A atividade segue as regras do jogo da memória, as 26 cartas são colocadas viradas para baixo, sendo um grupo com as cartas celestes e outro grupo com as cartas dos nomes das constelações, cada aluno deve virar uma carta de cada grupo, os pares são formados por uma carta com constelação tátil e outra com o nome da constelação, sendo ambas com transcrição em Braille. O aluno com DV deve ter um tempo maior para poder se localizar e fazer a identificação tátil. Quando aplicado somente ao aluno DV, o mesmo deve contar com a mediação do professor. Vence a rodada o aluno que conseguir encontrar mais pares.

\section{Considerações Finais}

As aulas de Astronomia requerem alunos participantes ativos, para que haja a transmissão e aprendizagem de seus conteúdos, sendo necessário muitas vezes que adaptações metodológicas visando a ludicidade sejam desenvolvidas através de materiais e jogos didáticos, para todos os estudantes, inclusive os com DV, que possuem suas peculiaridades e maneira de aprender através de manipulação e discriminação tátil. Pois, somente a oralidade, não permite a total compreensão de características e detalhes de alguns fenômenos relacionados com as Constelações e de informações a respeito dos astros, sendo importante em sala de aula que elementos visuais tenham seu equivalente textual ou tátil, para que a compreensão do que está sendo ensinado esteja o mais próximo possível de garantir o entendimento de situações abstratas.

Um dos objetivos deste trabalho foi identificar através da percepção do aluno com DV, a maneira ideal, de confeccionar o material adaptado, com as melhores condições de manuseio, compreensão, autonomia e aprendizagem. Podemos afirmar que a atividade prévia otimizou o processo, pois foram definidos tamanhos e materiais, sem correr o risco de que a elaboração do recurso estivesse distante das reais necessidades de aluno com DV. Os resultados evidenciaram que o jogo das Cartas táteis das Constelações do zodíaco e seus nomes, em formato de jogo da memória com regras já conhecidas por todos, é um instrumento pedagógico que pode proporcionar juntamente com a mediação do professor e participação dos demais alunos, o acesso aos conhecimentos de Astronomia de maneira lúdica com formato tátil e visual.

O jogo das Cartas táteis foi confeccionado com materiais de baixo custo e fáceis de serem encontrados em estabelecimentos comerciais. Tendo como um dos propósitos desta pesquisa, que a própria escola, com seus mecanismos de aquisição de materiais, proporcione que os professores seguindo o passo a passo façam modelos como este para serem aplicados em seus alunos com DV, e também quando possível em atividades que envolvam toda a turma.

Mediante várias pesquisas na área, ainda temos a carência de recursos adaptados táteis voltados para alunos com DV na área de ensino em Ciências. Dessa forma, será trazendo novas possibilidades para um ensino de Astronomia de maneira inclusivo, que os alunos com DV ou mesmo os videntes poderão ser beneficiados em suas aprendizagens e abstrações com uso de recursos didáticos. Ressalta-se aqui a importância de iniciativas que estimulem a elaboração de materiais táteis de temáticas variadas que contribuam para uma maior acessibilidade do conhecimento científico em Astronomia.

\section{Referências}

Alcará, A. R. \& Guimarães, S. E. R. (2007). A instrumentalidade como uma estratégia motivacional. Associação Brasileira de Psicologia Escolar e Educacional (ABRAPEE), 11(1), 177-8.

Barros, A. J. S. \& Lehefeld, N. A. S. (2014). Fundamentos de Metodologia Científica. 3 ed. São Paulo: Pearson Prentice Hall.

Brasil (2017). Ministério da Educação. Base Nacional Comum Curricular. Brasília: MEC/SEB.

Brasil (2004). Ministério da Educação. Decreto $n^{\circ}$ 5.296, de 2 de dezembro 2004. Regulamenta as Leis n. 10.048, de 8 de novembro de 2000, que dita prioridade de atendimento das pessoas que especifica, e 10.098, de 19 de dezembro de 2000, que estabelece normas gerais e critérios básicos para a promoção da acessibilidade das pessoas portadoras de deficiência ou com mobilidade reduzida, e dá outras providências. Brasília: Diário Oficial da União.

Brasil (2015). Ministério da Educação. Lei $n^{o}$ 13.146, de 6 de julho de 2015. Institui a Lei Brasileira de Inclusão da Pessoa com Deficiência (Estatuto da Pessoa com Deficiência). Brasília: Diário Oficial da União. 
Brasil, (2008). Ministério da Educação. Secretaria de Educação Especial. Política Nacional de Educação Especial na Perspectiva da Educação Inclusiva. Brasília: MEC/SEESP.

Brasil (2002). Ministério da Educação. Portaria n 2678, de 24 de setembro de 2002. Brasília: Diário Oficial da União.

Brasil (2007). Ministério da Educação. Sala de Recursos Multifuncionais: espaços para o Atendimento Educacional Especializado: Deficiência visual. Brasília: MEC/SEE.

Baumel. R. C. (1990). Habilidades do Professores dos Portadores de Deficiência Visual - Estado do Paraná. Tese (Doutorado) - Universidade de São Paulo, Programa de Pós-Graduação em Educação, São Paulo, SP, Brasil.

Revista Nova Escola (2020). Plano de Aula: constelações do zodíaco. https://novaescola.org.br/plano-de-aula/2773/constelacoes-do-zodiaco/sobre

Camargo, E. P. (2008). Ensino de Física e Deficiência Visual: dez anos de investigações no Brasil. São Paulo: Plêiade.

Campos, L.M., Felicio, A.K.C., \& Bortoloto, T.M. (2003). A produção de jogos didáticos para o ensino de ciências e biologia: uma proposta para favorecer a aprendizagem. Caderno dos Núcleos de Ensino, 35-48.

Costa, V. B. (2012). Inclusão Escolar do com deficiência visual no ensino regular. Jundiaí: Paco Editorial.

Costa, W. G. de C., Silva, R. A., \& Silva, L. C. (2021). "Tratando a água": Um jogo didático para o ensino de química com enfoque na abordagem Ciência, Tecnologia e Sociedade -CTS. Research, Society and Development, 10 (.4).

Dallabona, K. G. (2011). Inclusão de Deficientes Visuais no Curso Superior na Educação a Distância. Anais do XVII Congresso da Associação Brasileira de Educação a Distância.

Dorneles, C. M. A. (2014). Concepção Dos Professores Sobre In/Exclusão de Estudantes Com Deficiência Visual Na Educação Básica. 228f. Tese (Doutorado) - Universidade Católica Dom Bosco, Programa de Pós-Graduação em Educação, Campo Grande, MS, Brasil.

Duek, V. P. (2011). Educação Inclusiva e Formação Continuada: Contribuições dos casos de ensino para o processo de aprendizagem e desenvolvimento profissional de professores. 333p. Tese (Doutorado) - Universidade Federal do Rio Grande do Norte, Programa de Pós-Graduação em Educação, Natal, RN, Brasil.

Gasparetto, M. E. R. F. (2001). Visão subnormal em escolas públicas: conhecimentos, opinião e conduta de professores e diretores do ensino fundamental, 250p. Tese (Doutorado) - Universidade Estadual de Campinas. Faculdade de Ciências Médicas, Programa de Pós-Graduação em Ciências Médicas, Campinas, $\mathrm{SP}$, Brasil.

Gorgetti, M. G. (2005). Análise do desenvolvimento motor e social de adolescentes com deficiência visual e das atitudes dos professores de educação física: um estudo sobre a inclusão, 157f. Tese (Doutorado) - Universidade de São Paulo, Programa de Pós-Graduação em Educação Física, São Paulo, SP, Brasil.

Langhi, R., \& Nardi, R. (2012). Educação em Astronomia: repensando a formação de professores. São Paulo: Escrituras Editora.

Laplane, A. L. F. de, \& Batista, C. G. (2008). Ver, não ver e aprender: a participação de crianças com baixa visão e cegueira na escola. Cadernos Cedes, Campinas, 28(75), 209-227.

Mazzaro, J. L. (2007). Baixa Visão na Escola: Conhecimento e opinião de Professores e de Pais de alunos deficientes visuais, em Brasília, DF. Tese (Doutorado) - Universidade Estadual de Campinas, Faculdade de Ciências Médicas, Programa de Pós-Graduação em Ciências Médicas, Campinas, SP, Brasil.

Mazzotta, M. J. S. (2011). Educação Especial no Brasil: história e políticas públicas. 6. ed. São Paulo: Cortez.

Menezes, M. A. (2008). Formação de Professores de estudantes com necessidades educacionais especiais no ensino regular, 250p. Tese (Doutorado) Pontifícia Universidade Católica de São Paulo, Programa de Pós-Graduação em Educação (Currículo), São Paulo, SP, Brasil.

Moran, J. (2018). Metodologias ativas para uma aprendizagem mais profunda. In: Bacich, L., Moran, J (org.). Metodologias ativas para uma educação inovadora: uma abordagem teórico-prática. (p. 1-25).

Nunes, S. S. (2004). Desenvolvimento de conceitos em cegos congênitos: caminhos na aquisição do conhecimento. http://www.teses.usp.br/teses/disponiveis

Pagano, S.M., \& Martins, R.F.F. (2014). Imagem tátil tridimensional para o acesso de crianças cegas congênitas ao potencial comunicativo de imagens gráficas. Revista Benjamin Constant, Rio de Janeiro, ano 20, 57 (2), 127-137.

Pasini, F., \& Matos, M. A. S. (2014). “Tapando o sol com a peneira”: inclusão escolar no Estado de Rondônia. In: VI Congresso brasileiro de Educação Especial e IX Encontro Nacional dos Pesquisadores da Educação Especial, 11, São Carlos. Anais São Carlos.

Piletti, C. (2004). Didática geral. 23. ed. São Paulo: Ática.

Pimentel, A. G., \& Aragon, G. T. (2018). Jogos pedagógicos e a interação entre estudantes deficientes visuais e videntes. RevistAleph. XV (30), 254-269.

Ruiz, L. C., \& Batista, C. G. (2014). Interação entre crianças com deficiência visual em grupos de brincadeira. Revista Brasileira de Educação Especial, Marília, 20(2), 209-222.

Santos, J. A. \& Filho, D. P. (2017). Metodologia Científica. 2 ed. São Paulo: Cengage Learning.

Soares, K. D. de A., Castro, H. C., \& Delou, C. M. C. (2015). Astronomia para deficientes visuais: Inovando em materiais didáticos acessíveis. Revista Electrónica de Enseñanza de las Ciencias. Vol. 14, nº 3, p.377-391. 
Research, Society and Development, v. 10, n. 5, e18110514691, 2021

(CC BY 4.0) | ISSN 2525-3409 | DOI: https://doi.org/10.33448/rsd-v10i5.14691

Souza, S. E, \& Dalcolle G. A. V. G. (2007). O Uso de Recursos Didáticos no Ensino Escolar. Revista UNAM, 11, 110-114.

Uliana,, M.R., \& Mól, G.S. (2017). O processo educacional de estudante com deficiência visual: uma análise dos estudos de teses na temática. Revista Educação Especial, 30 (57), 145-162.

Urzêda, M. O. M. (2012). As políticas de Formação de professores para inclusão na perspectiva da diversidade social, 118 f. Dissertação (Mestrado) Universidade Católica de Goiás, Programa de Pesquisa e Pós-Graduação em Educação, Goiânia, GO, Brasil 